\title{
Trechos de Bohr sobre Modelos Atômicos: Indícios sobre como a Física é Construída e Possibilidades enquanto Recurso Didático
}

\section{Bohr Excerpts on Atomic Models: Indications on how Physics is Constructed and Possibilities as a Didactic Resource}

\author{
André Coelho da Silva ${ }^{a}$; Maria José P. M. de Almeida \\ a Instituto Federal de São Paulo, Itapetininga, Brasil - andrecoelho@ifsp.edu.br \\ b Universidade Estadual de Campinas, Campinas, Brasil-mjpmalmeida@gmail.com
}

Palavras-chave: Natureza da ciência. Textos originais de cientistas. Modelos atômicos. Leitura. Ensino de física.
Resumo: Tomando as abordagens históricas como uma das formas de fomentar a produção de sentidos sobre a Natureza da Ciência e embasados na noção de leitor virtual proveniente da Análise de Discurso, analisamos como aspectos sobre a construção da Física aparecem em trechos de uma obra de Niels Bohr. Neles, o autor sinalizou, entre outras coisas: a relação complexa entre teoria e experimento, as limitações da Ciência e seu caráter coletivo. Por inscrever seus pares como leitores virtuais do texto, este possui alta densidade conceitual e pressupõe o conhecimento do leitor sobre certos assuntos. Ainda assim, consideramos a possibilidade de sua leitura nos Ensinos Médio e Superior, especialmente se tiver como base a mediação do professor e adaptações que objetivem alterar o leitor virtual inscrito no texto

\section{Keywords:}

Nature of science. Original texts of scientists. Atomic models. Reading. Physics education.
Abstract: Taking historical approaches as one of the ways to foster the production of meanings about the Nature of Science and based on the notion of virtual reader from Discourse Analysis, we analyze how aspects on the construction of Physics appear in excerpts from a work by Niels Bohr. In them, the author signaled, among other things: the complex relationship between theory and experiment, the limitations of Science and its collective character. Due to inscribe their peers as virtual readers of the text, it has high conceptual density and assumes that the reader has knowledge about certain subjects. Nevertheless, we consider the possibility of its reading in High School and in undergraduate courses, especially if it is based on the teacher's mediation and adaptations that aim to change the virtual reader inscribed in the text. 


\section{Introdução}

A caracterização de como os conhecimentos científicos são produzidos tem sido alvo de dissenso ao longo da história. Ainda no final do século XVI, Francis Bacon e colaboradores procuraram sistematizar o que seria o Método Científico, isto é, o caminho que deveria ser seguido para desenvolver Ciência. Entre outras nomenclaturas, trata-se do que atualmente costuma ser chamado de método baconiano ou método empírico-indutivo, pois assume que um cientista deve efetuar muitas observações, sob diversas condições, de forma neutra e objetiva; e que as leis científicas são extraídas do conjunto de observações através de procedimentos de indução (CHALMERS, 1993).

Durante a primeira metade do século XX, o grupo de filósofos conhecido como Círculo de Viena procurou, entre outras coisas, aperfeiçoar ideias associadas ao método científico baconiano. Esse movimento, conhecido como positivismo lógico, empirismo lógico ou neopositivismo, exerceu e continua exercendo influência sobre a comunidade científica, apesar das severas críticas que tem recebido desde a década de 1930 (CHIBENI, s/d). Entre essas críticas estão as de que: não há definição acerca do número de observações necessárias de fato, alguns experimentos associados a teorias científicas aceitas atualmente ou ainda não foram realizados ou foram repetidos poucas vezes; não há definição acerca de que elementos devem ser variados a fim de garantir que as observações sejam feitas sob diversas condições é necessário variar a cor do cabelo do cientista? A cor de sua roupa? O que irá interferir no resultado? Ou seja: os cientistas realizam observações munidos de ideias prévias, de pressupostos teóricos (CHALMERS, 1993).

Contrapondo-se às ideias baconianas, Karl Popper e colaboradores desenvolveram outro modelo a fim de tentar explicar como a Ciência é desenvolvida e como um cientista deve trabalhar para desenvolvê-la. Esse método ficou conhecido como método hipotéticodedutivo ou falseacionismo. Assume-se que a Ciência começa com criações livres da mente (ideias, teorias), conjecturas especulativas das quais se devem deduzir situações individuais passíveis de testes empíricos - entendidos como não-neutros. Teorias refutadas por testes empíricos deveriam ser eliminadas. Teorias corroboradas pelos testes empíricos seriam entendidas como as melhores disponíveis e não como as verdadeiras. Trata-se, assim, de um modelo pautado em tentativa e erro (CHALMERS, 1993; CHIBENI, s/d).

Embora elimine as tão criticadas neutralidade e indução presentes no método empírico-indutivo, o método de Popper também costuma ser alvo de críticas. Destacamos duas delas: a subestimação do papel dos experimentos e das confirmações no desenvolvimento da ciência - aqueles entendidos como meros verificadores de teorias e as confirmações entendidas como não tendo efeito sobre a ampliação da confiança nelas; e o chamado problema de Duhem-Quine, que, grosso modo, indica que os testes empíricos e suas 
interpretações, assim como as teorias, estão sujeitos a falhas - logo, seria imprudente eliminar uma teoria após uma refutação, o que, de fato, não tem ocorrido ao longo da História da Ciência (CHALMERS, 1993; CHIBENI, s/d).

Durante o século XX, outros quatro epistemólogos atualmente bastante referenciados - inclusive na área de Educação em Ciências - propuseram suas ideias no que se refere à como se dá a produção dos conhecimentos científicos. Paul Feyerabend defendeu que não há um método científico universalmente válido, posicionando-se contra a instituição de um conjunto único, fixo e restrito de regras que constituiriam a forma de fazer Ciência. Já Imre Lakatos desenvolveu um modelo em que procurou aperfeiçoar o falseacionismo de Popper, dando conta das críticas que a ele foram desferidas (CHALMERS, 1993; REGNER, 1996; SILVEIRA, 1996).

Quanto a Thomas Kuhn e Ludwik Fleck, na apresentação de um livro sobre este, Condé (2012) indica que Kuhn utilizou aportes desenvolvidos por Fleck como base para seu famoso livro "A estrutura das revoluções científicas". Apesar disso, ainda segundo o autor:

[...] existem profundas diferenças entre os conceitos kuhnianos centrais de paradigma e mudança de paradigma, por um lado, e os conceitos fleckianos de estilo de pensamento e coletivos de pensamento, por outro [...] para Kuhn, a ciência se desenvolve por rupturas radicais e descontinuidades, isto é, através de mudanças de paradigmas [...] Para Fleck, no entanto, ideias trafegam de diferentes modos entre estilos de pensamento criados pelos diferentes coletivos de pensamento [...] (CONDÉ, 2012, p. 7)

A discussão sobre aspectos associados à construção, ao estabelecimento e à organização do conhecimento científico compõe o que se convencionou chamar de Natureza da Ciência. Compreendê-la envolve compreender do que a Ciência é feita, como ela é feita, de que forma ela influencia e é influenciada etc. (MOURA, 2014). Assumindo que um dos caminhos para fomentar a compreensão desses elementos é abordar episódios da História da Ciência e da Tecnologia (BAGDONAS et al., 2014; MOURA, 2014), objetivamos analisar como noções sobre a construção da Física aparecem, explícita ou implicitamente, em trechos de uma obra de Niels Bohr, pensando também se, de que forma e em que níveis de escolaridade esses trechos poderiam ser trabalhados.

$\mathrm{Na}$ próxima seção, listamos aspectos que, segundo a literatura, têm sido alvo de relativo consenso acerca do que caracteriza a Natureza da Ciência. Evidenciamos também o que tem sido dito a respeito da relevância em abordar a Natureza da Ciência nos processos de ensino e aprendizagem. Em seguida, pautados em obras de Eni Orlandi, apresentamos algumas noções da Análise de Discurso sobre as quais nos apoiamos para o desenvolvimento da pesquisa. Explicitamos também quais foram os trechos analisados, os motivos pelos quais eles foram escolhidos e os procedimentos de análise adotados. Por fim, apresentamos os resultados das análises realizadas e algumas considerações relativas ao objetivo proposto. 


\section{Natureza da Ciência e Ensino}

Diferentes epistemólogos caracterizam o que é Ciência, como ela é produzida e como ela se relaciona com o contexto sociocultural e histórico de formas diferentes, não havendo consenso total entre suas ideias. Por outro lado, haveria consenso parcial, isto é, consenso no que se refere a alguns aspectos da Natureza da Ciência. Em conjunto, tais aspectos consensuais entre diferentes epistemólogos constituem o que se convencionou chamar de visão consensual da Natureza da Ciência (LEDERMAN et al., 2002; OSBORNE et al., 2003; LEDERMAN; LEDERMAN, 2004; ABD-EL-KHALICK, 2012).

Entretanto, diversas críticas têm sido feitas à visão consensual. Entre elas as de que: a Ciência é tão complexa e dinâmica que um conjunto estático de aspectos não é capaz de descrevê-la; cada área de estudo científico possui suas particularidades, sendo inviável a proposição de aspectos consensuais a todas elas - pensar, por exemplo, na questão da experimentação e em suas diferentes perspectivas na Cosmologia e na Química; há falta de consenso sobre a intensidade com a qual os fatores socioculturais e históricos impactam a Ciência (EFLIN et al., 1999; RUDOLPH, 2000; VAN DIJK, 2011; BAGDONAS et al., 2014; MOURA, 2014).

Ainda que concordemos com essas críticas, acreditamos ser válido o esboço de características que possam fomentar processos de ensino e aprendizagem que sinalizem para uma visão mais coerente sobre a Ciência. Nesse sentido, influenciados por essas críticas, voltamo-nos para uma Ciência específica: a Física, assumindo que os cinco descritores apresentados a seguir com base em Pérez et al. (2001) e Moura (2014) são funcionais para designar aquilo que poderíamos chamar de natureza da Física ou, de forma mais específica, de Natureza da Física desenvolvida a partir de Galileu, Newton etc.:

I) Existem diversos métodos científicos e não um Método Científico enquanto receita padronizada e infalível para desenvolver conhecimento científico.

II) A relação entre ideias/teorias e observação/experimentação é complexa, uma não é consequência da outra. As teorias não são induzidas a partir das observações/experimentações, tampouco as observações/experimentações se resumem a mecanismos de teste das ideias/teorias.

III) Há na Ciência a busca por coerência global, isto é, por coerência com outros resultados, outras teorias, outras áreas etc.

IV) A Ciência influencia e é influenciada por aspectos históricos e socioculturais, não havendo neutralidade e objetividade total.

V) Os conhecimentos científicos estão sujeitos a mudanças e revisões, ou seja, possuem um caráter mutável e dinâmico. 
Paralelamente a esses aspectos assertivos, podemos mencionar também aspectos refutatórios que foram designados por Pérez et al. (2001) como visões deformadas sobre a Natureza da Ciência: visão empírico-indutivista e ateórica - como se as teorias fossem induzidas a partir de observações empíricas neutras; visão rígida - crença na existência do Método Científico; visão aproblemática e ahistórica - como se não houvessem controvérsias no âmbito da Ciência, como se o conhecimento científico fosse sinônimo de verdade; visão exclusivamente analítica, desprezando a busca por sínteses, por unificações; visão acumulativa de crescimento linear - como se a Ciência só fosse acumulando novos conhecimentos, sem rupturas, sem revisões; visão individualista e elitista da ciência - como se os cientistas fossem gênios que trabalham isolados do mundo; visão socialmente neutra da Ciência - como se os aspectos históricos e socioculturais não influenciassem os cientistas. Tendo em vista essas visões deformadas, acrescentamos um sexto descritor sobre a Natureza da Física:

VI) A Ciência é uma obra coletiva, envolve os precursores e os pares dos cientistas que trabalham em uma determinada área do conhecimento.

Tanto documentos oficiais associados ao ensino brasileiro - como os Parâmetros Curriculares Nacionais (PCN) -, quanto trabalhos desenvolvidos por pesquisadores da área de Ensino de Física/Ciências - como Köhnlein e Peduzzi (2005); Martins (2015); Arthury e Terrazzan (2018); Morais et al. (2018) - têm destacado a importância em abordar a Natureza da Ciência no Ensino Básico com o objetivo de proporcionar aos estudantes a construção de concepções mais adequadas sobre o que é Ciência, como ela é produzida, como ela funciona etc. Conforme apontamos anteriormente, um dos caminhos para que discussões sobre a Natureza da Ciência se façam presentes em salas de aula é por meio de abordagens de natureza histórica. Nesse sentido, pode-se recorrer a relatos produzidos por historiadores da Ciência, a materiais didáticos elaborados a partir dos relatos de historiadores, à leitura de textos produzidos pelos cientistas - costumeiramente nomeados de "originais de cientistas", entre outras possibilidades. Vale pontuar que, nos casos em que os textos escritos pelos cientistas são traduzidos, talvez fosse mais prudente chamá-los de "traduções de textos originais de cientistas" e não apenas de "textos originais de cientistas", uma vez que os processos de tradução de uma língua para outra não são totalmente objetivos/neutros.

Por fim, segundo Bagdonas et al. (2014), estudos têm indicado que discussões explícitas sobre a Natureza da Ciência em sala de aula são mais efetivas junto à desconstrução de concepções equivocadas e à construção de concepções mais adequadas sobre o tema em comparação a propostas implícitas - aquelas em que ficaria a cargo dos estudantes notar as "lições" implicitamente presentes sobre o que é Ciência e como ela funciona. Nesse contexto, autores como Duschl e Grandy (2013) têm se debruçado sobre diferentes perspectivas que 
visam tornar explícitas em sala de aula as discussões sobre a Natureza da Ciência. Ainda que difiram entre si em diversos aspectos, tais perspectivas parecem ter em comum a assunção da ideia de que não basta apresentar explicitamente aos estudantes adjetivos ou sentenças que supostamente caracterizariam a Ciência: é necessário que eles vivenciem experiências didáticas que possam embasar a construção de concepções mais adequadas sobre o tema.

\section{Apoio teórico-metodológico, corpus do estudo e procedimentos de análise}

Tomamos como apoio teórico-metodológico noções da linha da Análise de Discurso (AD) que teve Michel Pêcheux como um de seus principais articuladores. Baseamo-nos, especificamente, em noções divulgadas/produzidas no escopo dessa teoria por Eni Orlandi.

A AD foi articulada a partir de questões "[...] criadas pela relação entre três domínios disciplinares que são ao mesmo tempo uma ruptura com o século XIX: a Linguística, o Marxismo e a Psicanálise”. (ORLANDI, 2005, p. 19). Nela, não se separam forma e conteúdo e a linguagem é entendida como mediação entre o ser humano e a realidade social e natural. Já o sentido passa a ser entendido não como dado, mas como derivado da "inscrição da língua na história" (ORLANDI, 2005, p. 48). Dessa forma, a relação da linguagem com a exterioridade - as condições de produção do discurso - é essencial para a constituição do sentido. É a relação da linguagem com essas condições que levará à produção de determinados sentidos através de mecanismos que a $\mathrm{AD}$ visa compreender (ORLANDI, 1987).

Um desses mecanismos é o chamado mecanismo de antecipação. Trata-se da tentativa de se projetar no lugar de nosso interlocutor com o intuito de vislumbrar quais são os sentidos produzidos a partir da relação entre nossas palavras e as condições de produção. Assim, quando falamos/escrevemos, estruturamos o quê/como nos manifestamos levando em conta a imagem que construímos de nossos interlocutores, a projeção que construímos a respeito de como eles receberão nossas palavras e produzirão sentidos em uma dada situação. Com o objetivo de que nossos interlocutores nos interpretem da forma por nós esperada, utilizamos o mecanismo de antecipação como um fator que molda o quê/como vamos dizer. A essa noção, Orlandi (2000) relaciona a noção de leitor virtual: o leitor que o autor de um texto escrito inscreve em suas palavras com o intuito de antecipar o leitor real/efetivo da obra. Dessa forma, quando o leitor real/efetivo lê o texto produzido, ele interage com o leitor virtual que foi inscrito no texto pelo autor. Orlandi (2001, p. 61) aponta que:

[...] Não se pode falar do lugar do outro; no entanto, pelo mecanismo de antecipação, o sujeito-autor projeta-se imaginariamente no lugar em que o outro o espera com sua escuta e, assim, 'guiado' por esse imaginário, constitui, na textualidade, um leitor virtual que lhe corresponde, como um seu duplo. Esse é um jogo dos gestos de interpretação que se dá na ou a partir da materialidade mesma do texto e ao qual o analista deve ser sensível quando pensa o imaginário que constitui o sujeito leitor virtual e o sujeito leitor efetivo com suas determinações concretas. 
Sobre a leitura, atividade que consideramos central neste estudo, uma vez que a proposta envolve a leitura de trechos de uma obra de Bohr, a autora afirma que ela "[...] é o momento crítico da constituição do texto, pois é o momento privilegiado do processo da interação verbal: aquele em que os interlocutores, ao se identificarem como interlocutores, desencadeiam o processo de significação [...]”. (ORLANDI, 1983, p. 20).

A relevância que os estudos sobre a leitura têm tido na Educação em Ciências foi evidenciada no editorial de Almeida e Pagliarini (2016), texto em que, entre outros apontamentos, os autores lembram o amplo leque de investigações na área com essa abordagem e discutem sobre a relevância da linguagem chamada comum nas explicações para leigos em Física, conforme considerações do físico Werner Heisenberg, contemporâneo de Niels Bohr.

Apoiados no até aqui comentado, tomamos para análise trechos escritos por Niels Bohr em sua obra "Sobre a constituição de átomos e moléculas" (Bohr, 2001). Trata-se de um livro traduzido para a língua portuguesa (em Portugal) a partir do original em inglês publicado em 1963 - ano seguinte à morte de Bohr. Em sua versão portuguesa, a obra conta com um prefácio escrito por José Luis Rodrigues Martins, então professor de Física da Universidade de Luanda (Angola); e com uma introdução de sessenta páginas escrita por Léon Rosenfeld, físico contemporâneo de Bohr. Em seguida, são apresentadas as traduções de textos escritos por Bohr em 1913, época em que propôs um novo modelo atômico. Os escritos de Bohr estão divididos em quatro seções: uma Introdução e três trechos. Neste trabalho, apresentamos análises que tiveram como escopo a Introdução escrita por Bohr (p. 95-97) e a primeira parte de seu texto, denominada de "Ligação de electrões por núcleos positivos" (p. 98-129), cujo objetivo é discutir “[...] o mecanismo da ligação dos electrões a um núcleo positivo em relação com a teoria de Planck. [...]" (BOHR, 2001, p. 97).

Justificamos a escolha do texto analisado com base em dois aspectos: i) a relevância do tema modelos atômicos na Física e em seu ensino - constituindo-se, inclusive, como um tema de Física Moderna e Contemporânea, cuja abordagem sistemática no Ensino Médio e na formação de professores de Física já foi bastante justificada por trabalhos como Terrazan (1992), Valadares e Moreira (1998), Ostermann e Cavalcanti (1999), Pinto e Zanetic (1999), Machado e Nardi (2007), Pena (2007), Silva e Almeida (2011), Pagliarini e Almeida (2016) entre outros; e ii) a relevância de Bohr para a Física do século XX, devida tanto ao modelo atômico que propôs quanto ao desenvolvimento da Mecânica Quântica e de sua chamada interpretação de Copenhagen - interpretação da qual Bohr foi um dos principais defensores.

Consideramos que o público-alvo original do livro eram os pares de Bohr, até porque sua linguagem não é propriamente a usual na cotidianidade, envolvendo inclusive a metalinguagem da Física - alvo costumeiro de dificuldades por parte dos estudantes. Ainda 
assim, assumimos que narrativas historiográficas, como admitimos poder considerar essa obra,

[...] em funcionamento numa sala de aula, como mediadoras da memória discursiva dos estudantes, terão grande possibilidade de contribuir para associações, que eles farão com acontecimentos que desregulem os implícitos tão presentes na metalinguagem científica, provocando deslocamentos no discurso desses estudantes no sentido de melhor compreenderem, inclusive, essa mesma metalinguagem. (ALMEIDA, 2004, p. 339-340)

As análises dos trechos do livro foram feitas por meio da efetivação de dois procedimentos:

I) Análise de se e como os escritos de Bohr direcionam a produção de sentidos que guardam coerência com os seis aspectos que listamos como descritores da Natureza da Física: a inexistência de um único Método Científico; a relação complexa entre teoria e experimentação; a busca por coerência global; a existência de inter-relações com aspectos sócio-históricos e culturais; o caráter tentativo, mutável e dinâmico do conhecimento científico; e a produção coletiva da Ciência.

II) Identificação das características do leitor virtual inscrito por Bohr no texto, bem como de que forma essas características sinalizam possibilidades para a utilização do trecho analisado em sala de aula.

Em ambos os casos, transcrevemos alguns escritos de Bohr a fim de justificar e exemplificar as considerações formuladas.

\section{Análise de trechos de Bohr}

Bohr inicia a Introdução comentando sobre o modelo atômico de Rutherford e evidenciando o fato de que ele foi proposto como uma tentativa de explicar resultados experimentais:

Com a finalidade de explicar os resultados das experiências sobre a dispersão dos raios alfa pela matéria, o Prof. Rutherford criou uma teoria da estrutura dos átomos. [...] na verdade, como mostrou Rutherford, a hipótese da existência de núcleos, como os considerados, parece ser necessária para dar conta dos resultados das experiências [...] (BOHR, 2001, p. 95)

Vale mencionar que o modelo de Ernest Rutherford - que foi um dos orientadores de Bohr -, teve como principais méritos as proposições de que: um átomo possui um núcleo positivamente carregado; o núcleo possui dimensões reduzidas quando comparadas às de um átomo como um todo; quase a totalidade da massa de um átomo diz respeito à massa de seu núcleo; os elétrons (partículas eletricamente negativas) se movimentam ao redor do núcleo em órbitas circulares.

Outros trechos de Bohr também sinalizam a complexidade das relações entre teoria e experimento: 
A excelente concordância entre os valores calculados e os valores observados das razões entre os comprimentos de onda em questão parece ser um argumento forte a favor da validade do fundamento dos cálculos de Nicholson. No entanto, podem levantar-se objecções sérias contra a teoria. [...]. (BOHR, 2001, p. 103).

A segunda hipótese [a de que a passagem de um elétron de um estado estacionário para outro é seguido pela emissão de radiação] está em contraste evidente com as ideias habituais da electrodinâmica, mas parece ser necessária para explicar factos experimentais. (BOHR, 2001, p. 104).

Se o espectro considerado não se observa nos tubos de hélio usuais, é talvez porque, nesses tubos, a ionização do hélio não é tão completa como na estrela referida ou nas experiências de Fowler, nas quais se dá uma descarga forte através de uma mistura de hidrogênio e hélio. (BOHR, 2001, p. 109).

Vê-se que esta expressão abrange a lei que relaciona as riscas no espectro do hidrogênio. Escrevendo [...] obteremos séries situadas, respectivamente, no extremo ultravioleta e no extremo infravermelho, não observadas mas cuja existência deve esperar-se. (BOHR, 2001, p. 106).

O primeiro trecho transcrito evidencia que mesmo teorias que conseguem obter concordância com testes experimentais podem ser questionadas. O segundo evidencia que, em alguns casos, algumas hipóteses são assumidas de forma a garantir concordância com resultados experimentais, ainda que essas hipóteses contrastem com a teoria aceita em determinado momento histórico. O terceiro aponta que, em certos casos, os cientistas propõem hipóteses para explicar resultados experimentais inesperados, de maneira a tentar preservar a validade de suas teorias, tratando esses casos como exceções que ocorrem devido a determinados fatores. Já o quarto trecho evidencia que novas teorias também acabam prevendo situações ou fenômenos ainda não detectados experimentalmente, ou seja: além de explicar e ser coerente com fenômenos e resultados experimentais já alcançados, é importante que uma nova teoria também lance possibilidades outras ainda não experimentadas.

Ao longo do texto, Bohr aponta limitações associadas às teorias com as quais dialoga $\mathrm{e}$ até mesmo à sua teoria. No caso do modelo proposto por Rutherford, aponta como limitação a instabilidade decorrente do movimento dos elétrons ao redor do núcleo atômico. Acrescenta ainda que o modelo atômico de Thomson, proposto antes do de Rutherford, não possuía essa limitação:

Numa tentativa de explicar algumas das propriedades da matéria baseada neste modelo atómico deparamos, todavia, com dificuldades de natureza muito séria derivadas da aparente instabilidade do sistema de electrões: dificuldade deliberadamente evitada nos modelos atómicos previamente considerados como, por exemplo no proposto por Sir J. J. Thomson. [...] (BOHR, 2001, p. 95-96)

Há que se pontuar que o modelo de Joseph J. Thomson propunha que um átomo seria formado por uma esfera positivamente carregada na qual os elétrons estariam encrustados. Trata-se do modelo muitas vezes designado analogicamente como pudim de passas ou panetone. 
Outros trechos seguem nessa mesma direção de apontar limitações associadas a determinados conhecimentos científicos:

\begin{abstract}
A incapacidade da electrodinâmica clássica para explicar as propriedades dos átomos [...] (BOHR, 2001, p. 98).

Contudo, infelizmente sabemos muito pouco acerca do comportamento dos átomos de hidrogênio devido à fraca dissociação das moléculas de hidrogênio às temperaturas ordinárias. (BOHR, 2001, p. 122).
\end{abstract}

Consideramos que esses trechos podem conduzir o leitor à produção de sentidos que apontam para o caráter tentativo do conhecimento científico, evidenciando não somente seus sucessos explicativos e preditivos, mas também suas limitações.

Além de comentários sobre as diferenças entre os modelos de Thomson e Rutherford, Bohr também menciona trabalhos como os de John William Nicholson e de Max Planck, este, de trabalho tido como o marco inicial da Física Quântica. Consideramos que esses diálogos com os trabalhos de outros cientistas da época podem direcionar o leitor a produzir sentidos que apontam para o caráter coletivo da Ciência. Esse direcionamento também pode ocorrer a partir da indicação feita por Bohr de que quando há diferentes teorias disponíveis para tentar explicar fenômenos/resultados experimentais, é necessário argumentar para "convencer" os pares acerca dos motivos que levam uma a ser melhor que a outra. De fato, em alguns trechos, ele parece tentar convencer o leitor - supostamente seus pares - a assumir que seu modelo teórico era melhor que os outros propostos até então. Assim, inscreve no texto um leitor virtual capaz de avaliar as potencialidades e as limitações das opções em jogo, um leitor virtual que poderia tomar partido na disputa e até mesmo influenciar outros pares a aderirem a determinada posição:

[...] deve notar-se que a teoria [de Nicholson] na forma dada não parece ser capaz de explicar as bem conhecidas leis de Balmer e Rydberg [...] Tentar-se-á agora mostrar que as dificuldades em questão desaparecem se considerarmos os problemas sob o ponto de vista adoptado nesta memória. (BOHR, 2001, p. 103).

Grosso modo, a teoria de Nicholson mencionada por Bohr diz respeito à utilização da noção de quantização proposta por Max Planck para tentar explicar os comprimentos de onda de linhas espectrais (radiações) detectadas experimentalmente por meio de observações astronômicas da coroa solar e de nebulosas - mais detalhes sobre os trabalhos de Nicholson podem ser encontrados em Lopes e Martins (2007). Já as leis de Balmer e Rydberg são fórmulas que resultam em valores coerentes com os comprimentos de onda das linhas espectrais emitidas pelo átomo de Hidrogênio. À época, boa parte dessas linhas já havia sido detectada empiricamente.

Durante todo o trecho analisado, Bohr explicita o que o teria levado à proposição de seu modelo atômico. Nesse sentido, comenta dificuldades, faz hipóteses, assume postulados e dialoga com o trabalho de outros cientistas. Ou seja, aparentemente, as reflexões apresentadas 
têm o objetivo de levar o leitor a seguir sua linha de raciocínio, procurando evidenciar o processo que o levou a alcançar determinadas conclusões. Ainda que Bohr esteja se dirigindo a outros cientistas envolvidos no estudo da estrutura da matéria, a narrativa desse percurso, se for lida por estudantes, poderá proporcionar a oportunidade de discussões sobre a produção de modelos em Física, bem como do modo como eles vão se sucedendo. Pode, inclusive, contribuir para a discussão da metodologia científica e de questões epistemológicas de forma geral, abrangendo ou não teóricos como Kuhn, Fleck, entre outros, a critério do professor.

No que se refere à busca por coerência global, podemos notar que, ao longo do texto, Bohr procura evidenciar a importância de que as teorias científicas deem conta de explicar uma diversidade de fenômenos correlatos, recorrendo, para isso, a noções já bem estabelecidas em outros âmbitos - o apoio de Bohr na noção de quantização introduzida por Planck e desenvolvida por Einstein é um exemplo disso. Assim, ainda que de forma implícita, o trecho analisado pode fomentar junto aos leitores a produção de sentidos sobre a relevância da coerência interna na Ciência. Além disso, é uma questão que poderia ser melhor explorada com a mediação do professor no contexto de uma sala de aula. Segundo Orlandi (2000), a mediação efetuada pelo professor pode ser feita a partir de uma organização curricular que estabeleça, quando necessário, as relações intertextuais, resgatando a história dos sentidos e possibilitando ao aluno a construção de sua história de leituras para que, posteriormente, possa trabalhar dentro dela. A mediação a ser conduzida pelo professor entre o aluno e o conhecimento é entendida, portanto, como o estabelecimento/modificação das condições de produção de sentidos (ORLANDI, 1998).

Nas páginas analisadas, não encontramos nenhum trecho que pudesse evidenciar a inter-relação entre Ciência e aspectos socioculturais e históricos. Contudo, trata-se de algo que poderia ser explorado a partir de outros recursos, relacionando a preocupação científica em compreender os átomos e a estrutura atômica com o uso social da radioatividade, por exemplo.

O trecho analisado possui alta densidade conceitual, mencionando outros fenômenos físicos e resultados associados a outras teorias. Assim, consideramos que Bohr inscreve no texto um leitor virtual capaz de lidar com essa alta densidade conceitual, ou seja, um leitor virtual que já tenha produzido sentidos a respeito desses outros assuntos. Só na página 98, por exemplo, mencionam-se noções como frequência de revolução, eixo maior da órbita, quantidade de energia, radiação de energia, órbitas elípticas e energia cinética. Os trechos transcritos a seguir também ilustram essa densidade conceitual:

Vê-se que esta expressão abrange a lei que relaciona as riscas no espectro do hidrogênio. Se fixarmos [...] obtemos a série de Balmer. Se [...] obteremos a série observada por Paschen na região do infravermelho e previamente suspeitada por Ritz. Escrevendo [...] obteremos séries [...] não observadas mas cuja existência deve esperar-se. (BOHR, 2001, p. 106) 
[...] considerando o choque entre um electrão livre e um electrão ligado, concluir-seia que o electrão ligado não poderia adquirir pela colisão uma quantidade de energia menor do que a diferença de energia correspondente a estados estacionários sucessivos e, consequentemente, que o electrão livre que colide com ele não poderia perder uma quantidade menor do que essa. (BOHR, 2001, p. 121)

As séries referidas no primeiro trecho transcrito dizem respeito a linhas espectrais (radiações) emitidas pelo átomo de Hidrogênio. A série de Balmer se refere a radiações visíveis ao olho humano. Já a série de Paschen se refere a radiações invisíveis ao olho humano, mais especificamente a radiações na região do infravermelho do espectro eletromagnético. Balmer e Paschen elaboraram fórmulas que resultam em valores coerentes com os comprimentos de onda dessas linhas espectrais. Por conta disso, essas séries levam seus nomes.

Já o segundo trecho indica que um elétron que está ligado a um núcleo atômico pode receber apenas quantidades específicas de energia provenientes de elétrons livres (elétrons que não estão ligados a núcleos atômicos). Essas quantidades dizem respeito à diferença de energia entre órbitas eletrônicas de um dado átomo.

Vale notar que Bohr parece assumir a desnecessidade de esclarecimento acerca de certos elementos mencionados no texto, como sobre as séries de Balmer e Paschen, sinalizando novamente a inscrição de um leitor virtual inteirado sobre o tema. Dessa forma, ainda que a menção a outras noções/conceitos/teorias da Física possa ser um aspecto potencialmente positivo - pois possibilitaria que o professor retomasse elementos eventualmente já trabalhados ou procurasse trabalhar com assuntos ainda não abordados de maneira inter-relacionada, mediando a leitura dos estudantes -, uma densidade conceitual muito alta pode dificultar em demasia a produção de sentidos, levando o estudante até mesmo ao abandono da leitura (SILVA; ALMEIDA, 2014).

Outras possibilidades seriam modificar o trecho em questão a fim de reduzir sua densidade conceitual e/ou inserir explicações/detalhamentos sobre certas noções, resultados e teorias mencionadas. Independentemente da efetivação dessas possibilidades, quando pensado como um recurso didático para ser utilizado em sala de aula, defendemos a pertinência de que sejam selecionadas para leitura determinadas partes do texto analisado, uma vez que, como apontado por Silva e Almeida (2014), textos extensos tendem a levar os estudantes ao abandono da atividade e até mesmo à relutância em iniciá-la. O trecho completo poderia ser sugerido como uma tarefa de casa ou uma indicação de leitura. Outra sugestão é a de evitar trechos em que Bohr recorre ao formalismo matemático, pois se trata de um formalismo não muito simples, especialmente para estudantes do nível médio. Nesse sentido, o leitor virtual inscrito por Bohr em seu texto original possui um bom domínio da matemática envolvida, o que justifica a pertinência de que a leitura desses trechos seja mediada pelo professor ou de 
que eles sejam evitados - poder-se-ia adaptar o texto omitindo o formalismo matemático, mas dizendo que a partir dele se chegou até determinado resultado.

Em síntese, pautados nesses apontamentos, consideramos que o trecho analisado possa ser utilizado como recurso didático tanto na Física do Ensino Médio quanto na Física do Ensino Superior. Pelos motivos detalhados anteriormente, sugerimos, contudo, que essa utilização seja feita com a mediação do professor e com base em adaptações que visem alterar o leitor virtual inscrito no texto.

Em específico, consideramos que a utilização em sala de aula de textos construídos a partir do trecho analisado pode: fomentar discussões sobre a construção da ciência, proporcionando a produção de sentidos que guardem maior coerência com os aceitos na epistemologia atual; ilustrar a engenhosidade e a criatividade envolvidas na proposição de modelos atômicos, isto é, na proposição de qual seria a estrutura de algo que não enxergamos; abordar o modelo de Bohr, evidenciando que se trata de um modelo que mistura Física Clássica com Física Quântica; incentivar o gosto dos estudantes pela leitura, pelo fato de estarem lendo trechos escritos pelo próprio Bohr e pelo caráter narrativo do texto - o que o torna diferente de um livro didático (SILVA; ALMEIDA, 2005); proporcionar discussões sobre as limitações do modelo de Bohr, até porque, durante o texto, ele sugere que seu modelo poderia ser aplicado a qualquer átomo (atualmente sabemos que ele só funciona bem para átomos com um elétron - como o hidrogênio e o hélio ionizado).

\section{Considerações finais}

A pertinência de que o ensino de Física não se restrinja aos produtos (leis, equações, conceitos etc.) desenvolvidos pelos cientistas, mas que abarque também aspectos relativos aos processos adotados por eles parece ser consensual entre os pesquisadores dessa área. Nesse sentido, defendemos a relevância de estudos que investiguem e proponham possibilidades de como isso pode ser feito. Inserindo-nos nessa discussão, apontamos a leitura de trechos originais escritos por Bohr como forma de abordar os processos envolvidos na proposição dos modelos atômicos, fomentando junto aos estudantes a produção de sentidos não apenas sobre os produtos da Ciência, mas também de sentidos mais coerentes sobre seu funcionamento.

Como perspectivas para a continuidade deste trabalho, destacamos: a análise de outros trechos do mesmo livro e de obras escritas por outros cientistas; a elaboração de um texto destinado à Física do Ensino Médio tendo como base os escritos de Bohr; e a efetivação de propostas desse tipo com turmas do nível médio e com graduandos em Física, a partir das quais se poderia avaliar de que maneira as noções implícitas e explícitas sobre a construção da Ciência inscritas no texto atuam junto à produção de sentidos pelos estudantes. 


\section{Agradecimento}

Ao Conselho Nacional de Desenvolvimento Científico e Tecnológico (CNPq), pelo fomento - Projeto de Produtividade em Pesquisa.

\section{Referências}

ABD-EL-KHALICK, F. Examining the sources for our understandings about science: enduring conflations and critical issues in research on nature of science in science education. International Journal of Science Education, v. 34, n. 3, p. 353-374, 2012.

ALMEIDA, M. J. P. M. Historiografia e Interdiscurso. Ciência \& Educação, v. 10, n. 3, p. 333-340, 2004.

ALMEIDA, M. J. P. M.; PAGLIARINI, C. R.; Leitura na Educação em Ciências. Ciência \& Educação, v. 22, n. 2, p. 271-277, 2016

ARTHURY, L. H. M.; TERRAZZAN, E. A. A Natureza da Ciência na escola por meio de um material didático sobre a Gravitação. Revista Brasileira de Ensino de Física, v. 40, n. 3, p. 3403-21, 2018.

BAGDONAS, A.; ZANETIC, J.; GURGEL, I. Controvérsias sobre a natureza da ciência como enfoque curricular para o ensino da física: o ensino de história da cosmologia por meio de um jogo didático. Revista Brasileira de História da Ciência, v. 7, n. 2, p. 242-260, 2014.

BOHR, N. Sobre a Constituição de Átomos e Moléculas. Lisboa: Fundação Calouste Gulbenkian, 2001.

CHALMERS, A. F. O que é ciência, afinal? Trad. Raul Fiker. São Paulo: Editora Brasiliense, 1993.

CHIBENI, S. S. O que é ciência. s/d. Disponível em: <www.unicamp.br/ chibeni>. Acesso em: 30 jul. 2018.

CONDÉ, M. L. L. (Org.) Ludwik Fleck Estilos de Pensamento na Ciência. Belo Horizonte: Fino Traço Editora, 2012.

DUSCHL, R. A.; GRANDY, R. Two views about explicitly teaching Nature of Science. Science \& Education, v. 22, n. 9, p 2109-2139, 2013.

EFLIN, J.; GLENNAN, S.; REISCH, G. The nature of science: a perspective from the philosophy of science. Journal of Research in Science Teaching, v. 36, n. 1, p. 107-116, 1999.

KÖHNLEIN, J. F. K.; PEDUZZI, L. O. Q. Uma discussão sobre a natureza da ciência no ensino médio: um exemplo com a teoria da Relatividade Restrita. Caderno Brasileiro de Ensino de Física, v. 22, n. 1, p. 36-70, 2005.

LEDERMAN, N.; ADB-EL-KHALICK, F.; BELL, R. L.; SCHWARTZ, R. S. Views of Nature of Science Questionnaire: Towards valid and meaningful assessment of learners' conceptions of the nature of science. Journal of Research in Science Teaching, v. 39, n. 6, p. 497-521, 2002. 
LEDERMAN, N.; LEDERMAN, J. Revising instruction to teach nature of science: Modifying activities to enhance students' understanding of science. The Science Teacher, v. 71, n. 9, p. 36-39, 2004.

LOPES, C. V. M.; MARTINS, R. A. Uma lacuna na história dos modelos atômicos em livros didáticos: John William Nicholson e a astroquímica. In: VI ENCONTRO NACIONAL DE PESQUISA EM EDUCAÇÃO EM CIÊNCIAS (ENPEC), Florianópolis, 2007.

MACHADO, D. I.; NARDI, R. Construção e validação de um sistema hipermídia para o ensino de física moderna. Revista Electrónica de Enseñanza de las Ciencias, v. 6, n. 1, p. 90116, 2007.

MARTINS, A. F. P. Natureza da Ciência no ensino de ciências: uma proposta baseada em "temas" e "questões". Caderno Brasileiro de Ensino de Física, v. 32, n. 3, p. 703-737, 2015.

MORAIS, A. M.; NEVES, I. P.; FERREIRA, S.; SARAIVA, L. A natureza da ciência na educação em ciência: teorias e práticas. Práxis Educativa, v. 13, n. 1, p. 8-32, 2018.

MOURA, B. A. O que é natureza da Ciência e qual sua relação com a História e Filosofia da Ciência? Revista Brasileira de História da Ciência, v. 7, n. 1, p. 32-46, 2014.

ORLANDI, E. P. A produção da leitura e suas condições. Leitura, Teoria e Prática, v. 2, n. 1. p. $20-25,1983$.

ORLANDI, E. P. A linguagem e seu funcionamento: as formas do discurso. São Paulo: Pontes, 1987.

ORLANDI, E. P. Paráfrase e Polissemia: a fluidez nos limites do simbólico. Rua, v. 4, p. 919, 1998.

ORLANDI, E. P. Discurso e leitura. $5^{\text {a }}$ ed. São Paulo e Campinas: Cortez e Editora da UNICAMP, 2000.

ORLANDI, E. P. Apresentação: Cidade Atravessada. In: ORLANDI, E. P. (Org.). Cidade atravessada: os sentidos públicos no espaço urbano. Campinas: Pontes, 2001.

ORLANDI, E. P. Análise de discurso: princípios \& procedimentos. $6^{\text {a }}$ ed. Campinas: Pontes, 2005.

OSBORNE, J. F.; RATCLIFFE, M.; COLLINS, S.; MILLAR, R.; DUSCHL, R. What 'ideasabout-science' should be taught in school science? A delphi study of the 'Expert' community. Journal of Research in Science Teaching, v. 40, n. 7, p. 692-720, 2003.

OSTERMANN, F.; CAVALCANTI, C. J. H. Física moderna e contemporânea no ensino médio: elaboração de material didático, em forma de pôster, sobre partículas elementares e interações fundamentais. Caderno Catarinense de Ensino de Física, v. 16, n. 3, p. 267-286, 1999.

PAGLIARINI, C. R.; ALMEIDA, J. P. M. Leituras por alunos do ensino médio de textos de cientistas sobre o início da física moderna. Ciência \& Educação, v. 22, n. 2, p. 299-317, 2016. 
PENA, F. L. A. Por que, nós professores de Física do Ensino Médio, devemos inserir tópicos e ideias de física moderna e contemporânea na sala de aula? Revista Brasileira de Ensino de Física, v. 28, n. 1, p. 1-2, 2006.

PÉREZ, D. G.; MONTORO, I. F.; ALÍS, J. C.; CACHAPUZ, A.; PRAIA, J. Para uma imagem não deformada do trabalho científico. Ciência \& Educação, v. 7, n. 2, p. 125-153, 2001.

PINTO, A. C.; ZANETIC, J. É possível levar a Física Quântica para o ensino médio? Caderno Catarinense de Ensino de Física, v. 16, n. 1, p. 7-34, 1999.

REGNER, A. C. K. B. Feyerabend e o pluralismo metodológico. Caderno Catarinense de Ensino de Física, v. 13, n. 3, p. 231-247, 1996.

RUDOLPH, J. Reconsidering the "nature of science"' as a curriculum component. Journal of Curriculum Studies, v. 32, n. 3, p. 403-419, 2000.

SILVA, A. C.; ALMEIDA, M. J. P. M. Física Quântica no Ensino Médio: o que dizem as pesquisas. Caderno Brasileiro de Ensino de Física, v. 28, n. 3, p. 624-652, 2011.

SILVA, A. C.; ALMEIDA, M. J. P. M. A Leitura Por Alunos do Ensino Médio de Um Texto Considerado de Alto Grau de Dificuldade. Alexandria: Revista de Educação em Ciência e Tecnologia, v. 7, p. 49-73, 2014.

SILVA, H. C.; ALMEIDA, M. J. P. M. O deslocamento de aspectos do funcionamento do discurso pedagógico pela leitura de textos de divulgação científica em aulas de física. Revista Electrónica de Enseñanza de las Ciencias, v. 4, n. 3, p. 1-25, 2005.

SILVEIRA, F. L. A metodologia dos Programas de Pesquisa: a epistemologia de Imre Lakatos. Caderno Catarinense de Ensino de Física, v. 13, n. 3, p. 219-230, 1996.

TERRAZAN, E. A. A inserção da física moderna e contemporânea no ensino de Física na escola de 2ºu. Caderno Brasileiro de Ensino de Física, v. 9, n. 3, 1992.

VALADARES, E. C.; MOREIRA, A. M. Ensinando Física moderna no segundo grau: Efeito fotoelétrico, laser e emissão de corpo negro. Caderno Catarinense de Ensino de Física, v. 15, n. 2, p. 121-135, 1998.

VAN DIJK, E. M. Portraying real science in science communication. Science Education, v. 95, n. 6, p. 1086-1100, 2011.

\section{SOBRE OS AUTORES}

ANDRÉ COELHO DA SILVA. Doutor em Educação pela Faculdade de Educação da Unicamp (FE, Unicamp). Atuou como professor em instituições de ensino superior e em escolas de ensino fundamental e médio, tanto da rede pública como da rede privada. Foi coordenador do Programa Institucional de Bolsas de Iniciação à Docência (PIBID/CAPES) e orientador do Programa de Residência Pedagógica (PRP/CAPES) no Instituto Federal de São Paulo (IFSP), subprojeto Física, núcleo Itapetininga. Currículo Lattes: http://lattes.cnpq.br/7872731604284920. ORCID: http://orcid.org/0000-0003-1354-4034

MARIA JOSÉ P. M. DE ALMEIDA. Professora Titular aposentada. Atualmente atua como Colaboradora nos programas de pós-graduação da Faculdade de Educação da Unicamp e no 
Programa Multiunidades em Ensino de Ciências e Matemática - PECIM. É bolsista de produtividade em pesquisa 1B do Conselho Nacional de Desenvolvimento Científico e Tecnológico CNPq. Currículo Lattes: http://lattes.cnpq.br/6593952657486300. ORCID: http://orcid.org/0000-0001-7652-4730

Recebido: 06 de março de 2019.

Revisado: 24 de outubro de 2019.

Aceito: 10 de dezembro de 2019. 